\title{
Auditory characteristics of individuals with temporomandibular dysfunctions and dentofacial deformities
}

Tatiane Tottaํ, Giselda Santiago², Eduardo Sanches Gonçales ${ }^{3}$, Sandra de Oliveira Saes4, Giédre Berretin-Felix

\begin{abstract}
Objective: To investigate whether there is any relationship between otological as well as vestibular symptoms, audiological findings and type of temporomandibular disorder (articular, muscular and mixed); and to check the distribution of the temporomandibular disorders (TMD) dysfunction degree in the research population. Methods: A retrospective study involving 30 patients of both sexes, aged between 18 and 49 years old, diagnosed with TMD and dentofacial deformities, who were subject to clinical evaluation (muscle palpation, auscultation of temporomandibular joint during mandibular motion and measurement of jaw movement), audiological testing (pure tone audiometry and immittance testing) and two questionnaires, one on otological and vestibular symptoms and the other on TMD anamnesis. Based on both the anamnesis questionnaire and the clinical assessment, the subjects were divided according to the type and degree of TMD dysfunction (mild, moderate and severe), and compared regarding the occurrence of auditory signs and symptoms, vestibular symptoms and audiological findings according to TMD type. Results: The anamnesis questionnaire demonstrated higher prevalence $(83.33 \%)$ of severe TMD. Subjects with mixed TMD had more complaints about hypoacusis than those with muscular TMD ( $p<0.05)$. The results showed no change in either audiological and immittance testing for all assessed individuals. Conclusion: Otological symptoms are present in subjects with TMD and dentofacial deformities, regardless of the classification of TMD (articular, muscular or mixed). Those with mixed TMD may have higher incidence of complaints about hypoacusis than subjects with muscular TMD. Further studies are needed to investigate the relationship between otological symptoms and the different types of TMD.
\end{abstract}

Keywords: Temporomandibular joint disorders. Hearing disorders. Audiometry. Malocclusion.

Objetivo: investigar se há relação entre os sintomas otológicos, vestibulares, achados audiológicos e o tipo de disfunção temporomandibular (articular, muscular e misto), e verificar a distribuição do grau de disfunção da DTM nessa população. Métodos: estudo retrospectivo, envolvendo 30 pacientes com deformidades dentofaciais diagnosticados com DTM, de ambos os sexos, entre 18 e 49 anos de idade, submetidos a avaliação clínica (palpação muscular, ausculta da articulação temporomandibular durante os movimentos mandibulares e mensuração da movimentação da mandíbula), exame audiológico (audiometria tonal limiar e imitanciometria) e a dois questionários, sendo um sobre sintomas otológicos e vestibulares e outro anamnético da DTM. A partir do questionário anamnético e da avaliação clínica, os sujeitos foram divididos conforme o tipo e o grau da disfunção da DTM (leve, moderado e severo), e comparados quanto à ocorrência dos sinais e sintomas auditivos, vestibulares e achados audiológicos, de acordo com o tipo de DTM. Resultados: houve maior prevalência $(83,33 \%)$ de DTM severa de acordo com questionário anamnético. Sujeitos com DTM mista apresentaram mais queixas de hipoacusia do que aqueles com DTM muscular $(\mathrm{p}<0,05)$. Os resultados evidenciaram ausência de alterações nos exames audiológico e imitanciométrico para todos os indivíduos avaliados. Conclusão: sintomas auditivos estão presentes nos sujeitos com DTM e deformidades dentofaciais, independentemente da classificação da DTM (articular, muscular ou mista), e aqueles com DTM mista podem apresentar maior ocorrência de queixa de hipoacusia do que sujeitos com DTM muscular. Estudos futuros são necessários para investigar a relação entre a sintomatologia auditiva e os diversos tipos de DTM.

Palavras-chave: Transtornos da articulação temporomandibular. Transtornos da audição. Audiometria. Má oclusão.

\footnotetext{
${ }^{1}$ Postgraduate student in Rehabilitation Sciences, Craniofacial Anomalies Rehabilitation Hospital - University of São Paulo (HRAC-USP).

${ }^{2} \mathrm{MSc}$ in Rehabilitation Sciences, HRAC-USP.

${ }^{3}$ Associate Professor, Oral and Maxillofacial Surgery and Traumatology, Bauru School of Dentistry, University of São Paulo (FOB-USP).

${ }^{4}$ Professor, Speech Therapy, Sacred Heart University (USC).

${ }^{5}$ Associate Professor, department of Speech Therapy, Bauru School of Dentistry, University of São Paulo (FOB-USP).
}

Submitted: November 17, 2009 - Revised and accepted: April 27, 2011
How to cite this article: Totta T, Santiago G, Gonçales ES, Saes SO, Berretin-Felix G. Auditory characteristics of individuals with temporomandibular dysfunctions and dentofacial deformities. Dental Press J Orthod. 2013 SeptOct;18(5):70-7.

" The authors report no commercial, proprietary or financial interest in the products or companies described in this article.

Contact address: Giédre Berretin-Felix Alameda Dr. Otávio Pinheiro Brizolla, 9-75 Vila Universitária, Bauru/SP - Brazil CEP: 17012-901 -E-mail: gfelix@usp.br 


\section{INTRODUCTION}

Temporomandibular disorders (TMD) represent a set of clinical signs and multifactorial etiology symptoms characterized by pain in the temporomandibular joint (TMJ) and/or the tissue surrounding it, functional limitations in the jaw or crackling during TMJ movements. ${ }^{13}$ The usual classification, according to The American Academy of Orofacial Pain criteria, ${ }^{18}$ divides TMDs into groups according to anatomical etiology, respectively: Articular disorder, including the articular surface, the intra-articular disc or the articular bone; muscular disorder, involving the masticatory muscles surrounding the TMJ; or mixed disorder when there are signals of articular and muscular TMD. ${ }^{12}$

There are several factors involved in the etiology of TMD, such as disturbances of occlusion as well as maxillary and mandibular bone bases, degenerative disorder, traumatic factors, muscle disorders such as hyperactivity or hypoactivity, stress and emotional problems as well as functional changes and harmful habits that generate persistent overload in the TMJ or in the muscle.,12 Although the literature is discordant with regard to the real influence of malocclusion on the occurrence of TMD, a review carried out by McNamara et al ${ }^{15}$ related specific diagnostic groups of TMD to occlusal factors, such as skeletal anterior open bite, overjet greater than 6 to $7 \mathrm{~mm}$, difference between centric relation and maximal habitual intercuspation greater than $4 \mathrm{~mm}$, unilateral crossbite, and absence of five or more posterior dental elements. Regarding Angle's malocclusions, Thilander et $\mathrm{al}^{27}$ correlated Classes I, II and III to the prevalence of TMD and found higher prevalence of TMD in the group with Class III. However, the literature systematic review analysis of longitudinal studies conducted by Mohlin et $\mathrm{a}^{16}$ did not find significant clinical associations between different malocclusions, orthodontic treatment and signs and symptoms of TMD.

Auditory complaints and symptoms such as otalgia, tinnitus, hypoacusis, ear fullness and vertigo are often correlated to the presence of TMDs..$^{9,11,19,21,24,26,28,30}$

Several studies have been conducted in order to understand the etiology of auditory symptoms in subjects with TMD, firstly described by Costen. ${ }^{6}$ The author suggested that poor positioning of the mandibular condyle, caused by loss of posterior tooth support, could cause blockage of the Eustachian tube, symptoms of otalgia, tinnitus and vertigo. Later, Myrhaug ${ }^{17}$ stated that both stress and compression of the structures that conduct sound lead to increase in impedance, oftentimes causing ear fullness of floating feature associated with tinnitus. However, Penkner et $\mathrm{al}^{20}$ demonstrated that masticatory muscle spasms do not affect the function of the soft palate tensor muscle and the Eustachian tube.

More recently, other studies found an association between pain on palpation of the mandibular condyle and the presence of otalgia in TMD subjects. ${ }^{8,11,24} \mathrm{Ad}-$ ditionally, high prevalence of tinnitus and vertigo ${ }^{9,28,30}$ symptoms as well as ear fullness, ${ }^{8,14,25}$ was observed in the research population. These conditions may be related both to TMD signs, the presence of muscle tension, ${ }^{29}$ and pain on palpation in the masticatory muscles. ${ }^{14}$

With regard to hearing thresholds in subjects with TMD, the literature indicates lowering of airway thresholds in the frequencies of $6000 \mathrm{~Hz}$ and $8000 \mathrm{~Hz}{ }^{25}$ However, no changes in audiological testing and increased incidence of normal immittance were found. ${ }^{9}$

Although many studies have described auditory symptoms present in TMD patients, few studies have correlated the type of dysfunction (articular, muscle or mixed) to auditory signs and symptoms. Among them, Tuz et $\mathrm{a}^{28}$ have not found any prevalent occurrence of otalgia symptoms, tinnitus, vertigo or hearing loss among subjects classified as presenting articular, muscular and mixed TMD. On the other hand, the authors found higher prevalence of complaints in this population compared to the control group.

Hence, considering that skeletal malocclusion can be a contributing factor to TMD, this study aims to characterize the hearing function of individuals with TMD and dentofacial deformities according to each one of the TMD groups: articular, muscular or mixed (articular and muscular) and to investigate the distribution of the TMD dysfunction degree (mild, moderate or severe) in the studied population.

\section{MATERIAL AND METHODS}

The research subjects comprised 30 young adults of both sexes, clinically diagnosed with temporomandibular disorders by means of implementation of the Research Diagnostic Criteria for Temporomandibular Disorders (RDC/TMD) Axis $\mathrm{I}^{7}{ }^{7}$ and who presented dentofacial deformities characterized by skeletal Class II or Angle Class III malocclusion. Exclusion criteria encompassed individuals with a history of central or peripheral neurological disorders, trauma or tumors in the 
head and neck, noise exposure and early hearing-loss. This study was conducted at Universidade do Sagrado Coração/USC (Sacred Heart University) Bauru, Brazil, and was approved by the University Ethics Committee for Research on Human Beings (Protocol No. 077/2003).

Individuals were selected based on analysis of medical records of patients treated at the Oral and Maxillofacial Surgery Clinic of the College of Dentistry at the aforementioned university. These subjects had undergone a dental clinical evaluation and answered two questionnaires. One questionnaire was the Anamnesis Index (AI $)^{4,5}$ based on a modification of the Helkimo anamnesis index, ${ }^{10}$ and previously used by Conti et $\mathrm{al}^{4}$ at a significance level of $5 \%$; while the other investigated the history of otological and vestibular symptoms.

Clinical evaluation was performed by the same examiner, properly trained and calibrated, and considered the following: measurement of both maximum mouth opening and laterality, presence of mandibular deviation or deflection, TMJ(s) palpation, analysis of joint noises and bilateral palpation of the temporal muscles, masseter, posterior digastric muscle, medial pterygoid muscle, sternocleidomastoid and upper trapezius. Based on the aspects investigated in the interview and clinical evaluation, the TMD patients were diagnosed and classified according to The American Academy of Orofacial Pain criteria. ${ }^{18}$

- GI: Group with articular TMD - presence of disc displacement, limitation of maximum mouth opening (less than or equal to $35 \mathrm{~mm}$ ), mandibular deflection or deviation, spontaneous pain and/or upon TMJ palpation; cases with signs of myogenic TMD were excluded.

- GII: Group with muscular TMD - report of pain in the masticatory muscles during functional examination and/or muscle palpation; cases with arthrogenous TMD signs were excluded.

- GIII: Group with mixed TMD - signs of muscular and articular TMD.

Thus, the GI group (articular TMD) comprised 10 subjects, 7 with Angle Class II malocclusion and 3 with Angle Class III malocclusion. The GII group (muscular TMD) comprised 10 subjects, 4 with Class II and 6 with Class III. And finally, the GIII group (mixed TMD) comprised 10 subjects, 6 with Class II and 4 with Class III.
In the anamnesis index, the following aspects were investigated: Difficulty in mouth opening and jaw laterality, discomfort or muscle pain when chewing, presence of pain and/or muscle fatigue, perception of noise in the TMJ, headaches, neck or shoulder pain, pain in the ears (otalgia) or near them, use of one side of the mouth for chewing, facial pain in the morning and whether the subject considered his bite as normal. 5,12,26 Three possible answers were offered: "yes", "no" and "sometimes"; each "yes" corresponding to 2 points, "sometimes" represented 1 point and "no" represented 0 . The items related to frequent headaches, earaches or close to it, and the presence of TMJ noises had a total of 3 points when they were bilaterally or intensively referred. ${ }^{4}$ The sum of points allowed the classification of subjects into no-TMD $(0$ to 3 points), mild TMD (4-8 points), moderate TMD (9-14 points) and severe TMD (15 to 23 points). ${ }^{4}$

For specific investigation on ontological and vestibular symptomatology, the subjects were interviewed by a speech therapist who considered the presence of the following symptoms: vertigo and/ or dizziness, tinnitus, ear fullness, earache and hypoacusis. They were also submitted to hearing evaluation at the Center of Health Education (CEPS), Bauru, Brazil, at properly equipped and acoustically treated rooms. The subjects underwent otoscopic examination, pure tone audiometry, logoaudiometry and immittance testing, using the GSI-60 audiometer and AZ-7 imittanciometer.

Pure tone audiometry determines the least quantity of audible acoustic energy (hearing threshold), ${ }^{23}$ through the analysis of hearing thresholds for air and bone conduction of each frequency, using pure tones that are generated by two monaural headphones. The subject is instructed to raise his hand to the evaluator every time he listens to the tone stimulus. The evaluator reduces the signal strength tone, decreasingly, in values ranging from 10 to $10 \mathrm{~dB}(\mathrm{HL})$ until the hearing threshold is found. There must be confirmation of response in $50 \%$ of the 4 stimulation trials and the maximum hearing threshold value of $20 \mathrm{~dB}(\mathrm{HL})^{24}$ should be considered as normal.

The logoaudiometry is a test of speech discrimination. For this study, the Speech Reception Threshold (SRT) test parameters were evaluated: Speech stimulus has its intensity reduced until is found the 
lowest intensity, in which the subject can discriminate $50 \%$ of the words dictated to him. The Speech Recognition Index (SRI) test parameters were also evaluated: the subject must repeat a list of 25 monosyllabic words (for each ear), in the same intensity, $40 \mathrm{~dB}$ above the tonal threshold mean of the following frequencies: 500, 1000 and $2000 \mathrm{kHz} .^{23}$

Immittance testing represents an indirect test of tubal function, capable of evaluating both static and dynamic air pressure in the middle ear. This exam measures the ability of the tympanic membrane to reflect a sound introduced into the outer acoustic meatus, in response to gradual changes of pressure in the same space, thus, verifying the permeability of the tympanic-ossicular system with the passage of a sound wave within normal limits. ${ }^{23}$

The criteria used to define changes in the audiological tests were the following: Pure tone air-conduction thresholds (in the frequencies of $250 \mathrm{~Hz}$, $500 \mathrm{~Hz}, 1000 \mathrm{~Hz}, 2000 \mathrm{~Hz}, 3000 \mathrm{~Hz}, 4000 \mathrm{~Hz}$, $6000 \mathrm{~Hz}$ and $8000 \mathrm{~Hz}$ ) and pure tone bone-conduction (in the frequencies of $500 \mathrm{~Hz}, 1000 \mathrm{~Hz}$, $2000 \mathrm{~Hz}$ and $4000 \mathrm{~Hz}$ ) greater than $20 \mathrm{~dB}(\mathrm{HL})$; air-bone GAP greater than $10 \mathrm{~dB}(\mathrm{HL})$; Speech Recognition Index (SRI, monosyllables) lower than 92\%, SRT with values above $20 \mathrm{~dB}$; tympanometric curve deviated from -100 daPa; contralateral acoustic reflexes exceeding $115 \mathrm{~dB}(\mathrm{HL})$ (absent); difference between the pure tone air-conduction threshold and reflex threshold less than $60 \mathrm{~dB}(\mathrm{HL})$, which would be suggestive of recruitment. ${ }^{9}$

Table 1 - Distribution of subjects in accordance with Helkimo Anamnesis Index for each group.

\begin{tabular}{ccccccc}
\hline & \multicolumn{5}{c}{ Dysfunction severity } \\
\cline { 2 - 7 } Type & \multicolumn{2}{c}{ Mild } & \multicolumn{2}{c}{ Moderate } & Severe \\
\cline { 2 - 7 } & $n$ & $\%$ & $n$ & $\%$ & $n$ & $\%$ \\
\hline Articular & 1 & $3.33 \%$ & 1 & $3.33 \%$ & 8 & $26.67 \%$ \\
\hline Muscular & 0 & $0 \%$ & 3 & $10 \%$ & 7 & $23.33 \%$ \\
\hline Mixed & 0 & $0 \%$ & 0 & $0 \%$ & 10 & $33.33 \%$ \\
\hline Total & 1 & $3.33 \%$ & 4 & $13.33 \%$ & 25 & $83.33 \%$ \\
\hline
\end{tabular}

Data analysis was performed by means of descriptive statistics, parametric and nonparametric. To compare the occurrence of auditory and vestibular symptoms according to the three different groups of TMD, the analysis of variance (ANOVA) was applied, as a classification criterion adopting a significance level of $p<0.05$. To compare the TMD groups regarding the severity of TMJ disorder, the nonparametric Kruskal-Wallis test was applied, considering $p<0.05$. Friedman test was used to investigate the tympanometric results, considering $p<0.01$.

\section{RESULTS}

The study comprised 30 subjects of both sexes, 24 women and 6 men, aged 18-49 years (mean $27.3 \pm 7.05$ years), divided into 3 groups: GI (10 subjects with articular TMD), GII (10 subjects with muscular TMD) and GIII (10 subjects with mixed TMD).

With regard to the anamnesis index, it was verified higher prevalence of subjects presenting severe symptoms of dysfunction for the three TMD groups studied, as shown in Table 1 . However, no statistically significant difference $(p=0.069)$ was found among them.

Additionally, symptoms of moderate dysfunction occurred in one subject of GI group (10\%) and in three subjects of GII group (30\%). Mild dysfunction was observed for one subject of GI group (10\%), only.

Individuals of articular (GI), muscular (GII) and mixed (GIII) TMD groups were questioned regarding the audiological and vestibular symptoms (Fig 1), and tinnitus and vertigo were reported by most subjects.

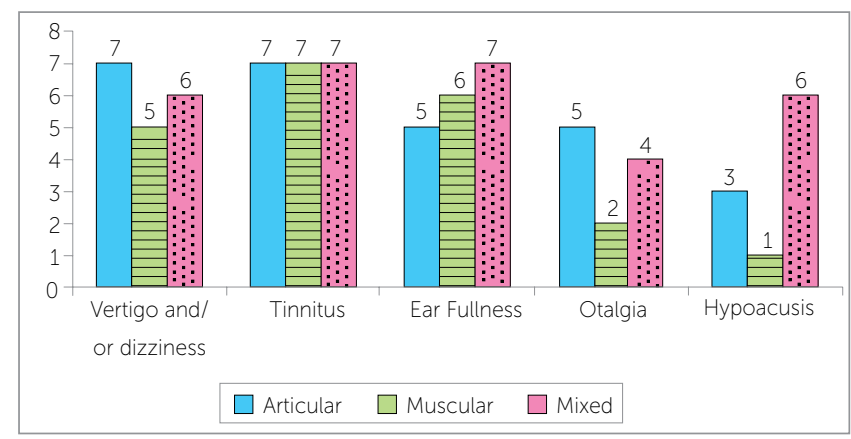

Figure 1 - Distribution of subjects with audiological and vestibular symptoms according to the three different groups of TMD. 
Table 2 - Distribution of pure tone air conduction thresholds for all frequencies of each individual from the Gl (articular), Gll (muscular) and Glll (articular and muscular) groups for the right (RE) and left ears (LE).

\begin{tabular}{|c|c|c|c|c|c|c|c|c|c|}
\hline \multirow{2}{*}{$\begin{array}{l}\text { Subjects/ } \\
\text { Groups }\end{array}$} & \multirow{2}{*}{ Ears } & \multicolumn{8}{|c|}{ Frequency } \\
\hline & & 250 & 500 & 1.000 & 2.000 & 3.000 & 4.000 & 6.000 & 8.000 \\
\hline \multirow{2}{*}{$1 / \mathrm{Gl}$} & $\mathrm{RE}$ & 5 & 10 & 10 & 15 & 10 & 5 & 5 & 10 \\
\hline & LE & 5 & 15 & 5 & 15 & 0 & 5 & 10 & 10 \\
\hline \multirow{2}{*}{$2 / \mathrm{Gl}$} & $\mathrm{RE}$ & 10 & 10 & 5 & 10 & 10 & 5 & 10 & 10 \\
\hline & LE & 5 & 5 & 10 & 5 & 10 & 10 & 5 & 10 \\
\hline \multirow{2}{*}{$3 / \mathrm{Gl}$} & $\mathrm{RE}$ & 10 & 5 & 10 & 5 & 5 & 0 & 10 & 10 \\
\hline & LE & 15 & 10 & 10 & 5 & 5 & 5 & 10 & 5 \\
\hline \multirow{2}{*}{$4 / \mathrm{Gl}$} & $R E$ & 0 & 0 & 0 & 0 & 0 & 0 & 0 & 5 \\
\hline & LE & 5 & 5 & 0 & 0 & 0 & 5 & 5 & 5 \\
\hline \multirow{2}{*}{$5 / \mathrm{Gl}$} & $\mathrm{RE}$ & 10 & 10 & 5 & 10 & 15 & 10 & 10 & 10 \\
\hline & LE & 0 & 10 & 5 & 10 & 15 & 5 & 5 & 10 \\
\hline \multirow{2}{*}{$6 / \mathrm{Gl}$} & $\mathrm{RE}$ & 0 & 0 & 0 & 0 & 0 & 0 & 0 & 0 \\
\hline & LE & 10 & 10 & 10 & 5 & 5 & 5 & 0 & 5 \\
\hline \multirow{2}{*}{$7 / \mathrm{Gl}$} & $\mathrm{RE}$ & 10 & 10 & 5 & 0 & 5 & 0 & 10 & 5 \\
\hline & LE & 5 & 10 & 5 & 10 & 5 & 10 & 10 & 10 \\
\hline \multirow{2}{*}{$8 / \mathrm{Gl}$} & $\mathrm{RE}$ & 10 & 0 & 10 & 15 & 10 & 10 & 5 & 5 \\
\hline & LE & 10 & 10 & 5 & 10 & 10 & 15 & 10 & 10 \\
\hline \multirow{2}{*}{$9 / \mathrm{Gl}$} & RE & 5 & 5 & 10 & 10 & 10 & 15 & 10 & 10 \\
\hline & LE & 5 & 10 & 5 & 10 & 5 & 5 & 10 & 10 \\
\hline \multirow{2}{*}{$10 / \mathrm{Gl}$} & $\mathrm{RE}$ & 0 & 5 & 10 & 10 & 15 & 10 & 10 & 10 \\
\hline & LE & 10 & 10 & 15 & 10 & 10 & 15 & 10 & 10 \\
\hline & $\mathrm{RE}$ & 15 & 15 & 10 & 10 & 10 & 5 & 5 & 10 \\
\hline 11 / Gll & LE & 15 & 15 & 10 & 10 & 5 & 10 & 5 & 5 \\
\hline & $\mathrm{RE}$ & 10 & 10 & 10 & 10 & 5 & 5 & 10 & 10 \\
\hline 12 / Gll & LE & 10 & 10 & 10 & 5 & 5 & 5 & 20 & 20 \\
\hline & RE & 15 & 15 & 10 & 5 & 5 & 10 & 5 & 5 \\
\hline 15 / Gll & LE & 15 & 15 & 10 & 5 & 10 & 5 & 15 & 10 \\
\hline & $\mathrm{RE}$ & 10 & 10 & 10 & 5 & 5 & 5 & 10 & 10 \\
\hline 14 / Gll & LE & 10 & 5 & 5 & 5 & 10 & 10 & 5 & 10 \\
\hline & $\mathrm{RE}$ & 0 & 5 & 10 & 5 & 5 & 10 & 5 & 5 \\
\hline 15 / Gll & LE & 0 & 5 & 10 & 10 & 0 & 10 & 10 & 5 \\
\hline & $\mathrm{RE}$ & 0 & 5 & 5 & 5 & 10 & 5 & 5 & 10 \\
\hline $16 /$ Gll & LE & 0 & 5 & 10 & 10 & 5 & 5 & 10 & 10 \\
\hline & $\mathrm{RE}$ & 10 & 5 & 10 & 10 & 10 & 5 & 15 & 10 \\
\hline 1/ / Gll & LE & 5 & 5 & 10 & 5 & 10 & 5 & 10 & 10 \\
\hline & $\mathrm{RE}$ & 10 & 15 & 10 & 10 & 5 & 10 & 10 & 10 \\
\hline 18 / Gll & LE & 5 & 10 & 5 & 10 & 10 & 10 & 10 & 10 \\
\hline & $\mathrm{RE}$ & 10 & 10 & 10 & 10 & 10 & 10 & 15 & 15 \\
\hline 19 / Gll & LE & 10 & 0 & 5 & 5 & 5 & 5 & 10 & 10 \\
\hline & $\mathrm{RE}$ & 10 & 10 & 10 & 10 & 15 & 5 & 15 & 10 \\
\hline 20 / Gll & LE & 10 & 5 & 10 & 15 & 10 & 15 & 10 & 10 \\
\hline & $\mathrm{RE}$ & 5 & 10 & 5 & 5 & 5 & 5 & 0 & 5 \\
\hline 21 / GIII & LE & 5 & 10 & -5 & 0 & 5 & 5 & 5 & 5 \\
\hline 22 / GIII & $\mathrm{RE}$ & 10 & 5 & 10 & 5 & 5 & 10 & 10 & 10 \\
\hline $22 / \mathrm{GIII}$ & LE & 15 & 10 & 10 & 5 & 5 & 5 & 10 & 5 \\
\hline & $\mathrm{RE}$ & 5 & 5 & 0 & 0 & 5 & 5 & 5 & 10 \\
\hline $23 / \mathrm{Glll}$ & LE & 5 & 5 & 5 & 5 & 10 & 10 & 10 & 10 \\
\hline & $\mathrm{RE}$ & 0 & 0 & 0 & 5 & 5 & 5 & 0 & 10 \\
\hline 24 / GIII & LE & 5 & 5 & 5 & 5 & 5 & 10 & 5 & 5 \\
\hline & $\mathrm{RE}$ & 10 & 10 & 10 & 15 & 10 & 10 & 10 & 10 \\
\hline $25 / G \| l \mid$ & LE & 10 & 0 & 10 & 10 & 10 & 10 & 10 & 10 \\
\hline & $\mathrm{RE}$ & 5 & 5 & 10 & 5 & 10 & 5 & 5 & 10 \\
\hline $26 / G I I I$ & LE & 5 & 10 & 10 & 5 & 5 & 10 & 10 & 10 \\
\hline & $\mathrm{RE}$ & 10 & 5 & 5 & 0 & 5 & 0 & 10 & 5 \\
\hline 2// Gill & LE & 5 & 10 & 5 & 5 & 5 & 10 & 5 & 5 \\
\hline & $\mathrm{RE}$ & 10 & 5 & 10 & 0 & 10 & 10 & 10 & 10 \\
\hline 28 / GIII & LE & 15 & 15 & 10 & 5 & 10 & 10 & 10 & 10 \\
\hline & $\mathrm{RE}$ & 10 & 10 & 5 & 10 & 15 & 5 & 5 & 10 \\
\hline 29 / GIII & LE & 0 & 10 & 5 & 10 & 15 & 5 & 5 & 10 \\
\hline & $\mathrm{RE}$ & 0 & 0 & 5 & 5 & 10 & 5 & 10 & 10 \\
\hline $30 /$ Glll & LE & 5 & 5 & 10 & 10 & 10 & 10 & 15 & 10 \\
\hline
\end{tabular}


Furthermore, otalgia and hypoacusis were less frequently reported for individuals with muscular TMD. Statistical analysis showed that subjects with mixed TMD have more complaints about hypoacusis when compared to subjects with muscular TMD $(p=0.0581)$.

In regard to pure tone audiometry, the subjects of the three TMD groups showed, for both ears, hearing thresholds ranging between 5 and $20 \mathrm{~dB}(\mathrm{HL})$, for all air-conduction frequencies tested (Table 2).

As for pure tone bone-conduction thresholds, all subjects presented normal compatible values and showed air-bone GAP lower than $10 \mathrm{~dB}(\mathrm{HL})$ for all frequencies tested.

In logoaudiometry, the Speech Recognition Index found for all individuals showed values between 96\% and $100 \%$ of accuracy, which is consistent with the references of normality. Similarly, normal results in SRT (between 0 and $20 \mathrm{~dB}(\mathrm{HL})$ ) were observed for the entire sample. The immittance testing showed significant prevalence $(p=0.0001)$ of type A curve, representing consistent results with normal values.

\section{DISCUSSION}

In this study, patients were divided into groups according to TMD classification (articular, muscular and mixed) and dysfunction severity (mild, moderate and severe), aiming at elucidating the relationship between audiological / vestibular signs and symptoms and the different types of TMD.

In this sample there was higher incidence of TMD in females (80\%) compared to males $(20 \%)$, and this prevalence is very close to the values reported in the literature, since many studies have shown that TMD signs and symptoms are more common in women aged between 20 to 39 years old. . $17,20,21,26^{2}$

Twenty four women were evaluated in this study, 15 (50\%) of which aged between 20 and 29 years old, who were diagnosed with TMD. This result corroborates those obtained by Williamson ${ }^{29}$ and Felício. ${ }^{8}$

There is also the hypothesis that degradation of cartilage and articular bone, due to menopause and increase in estrogen and prolactin, ${ }^{17}$ may be related to the presence of TMD symptoms in women aged 40-49 years. In this sample, such symptoms were observed in $2(6.67 \%)$ women within this age range.

With regard to the degree of dysfunction, 25 subjects $(88.33 \%)$ of the sample, among the different groups, showed severe TMD symptoms. The study carried out by Penkner et $\mathrm{a}^{20}$ found higher prevalence of moderate dysfunction, followed by severe dysfunction, among evaluated subjects with TMD. Keersmaekers et a ${ }^{11}$ also measured the symptoms in TMD, by means of applying the Pain and Dysfunction Index, ${ }^{10}$ and found significant higher prevalence of severe dysfunction in individuals with TMD concomitant with otalgia, when compared to subjects without otalgia. On the other hand, Silveira et $\mathrm{a}^{26}$ found higher severity rate of mild TMD, followed by absent, moderate and severe TMD, respectively, in a sample of patients treated in an otorhinolaryngology outpatient unit. To carry out this evaluation, the authors used the same anamnesis questionnaire of the present research. Conti et $\mathrm{al}^{5}$ investigated the association between malocclusion (Class I and Class II), orthodontic treatment, prevalence and severity of TMD signs and symptoms in 200 adolescents. They found that $34 \%$ of them had mild symptoms, according to the anamnesis index applied, while 3.5\% had moderate symptoms. The lack of agreement in the literature regarding the degree of TMD prevalence may be related to the different conditions presented by the subjects of the cited studies, and it is important to consider that this study investigated individuals with dentofacial deformities.

As for the auditory and vestibular symptoms, it was found that more than half of the subjects in each studied group had symptoms of vertigo and/or dizziness, tinnitus and ear fullness. Pereira et $\mathrm{al}^{21}$ also observed $65 \%$ of prevalence of tinnitus, otalgia and ear fullness in patients with TMD, as well as Parker and Chole ${ }^{19}$ found significant prevalence of tinnitus and vertigo in patients with TMD. A study carried out by Tuz et $\mathrm{a}^{28}$ also subdivided the subjects according to the types of TMD and found no predilection of audiological symptoms of otalgia, tinnitus, vertigo and hearing loss among groups with muscular, articular or mixed TMD. However, these symptoms were greatly prevalent in the control group of subjects without TMD. Nevertheless, Felício et $\mathrm{al}^{9}$ found a relationship between subjects with severe pain in muscles and in TMJ, and the propensity for otalgia and tinnitus.

According to the literature, the complaint of ear fullness may be due to muscle changes in patients with TMD, such as the lateral pterygoid muscle spasm, leading to hypertonia of the tensor tympani muscle, causing changes in the cycle of Eustachian tube opening and leading to reduction in ventilation of the middle ear. ${ }^{17}$ However, the study of Penkner et a ${ }^{20}$ refutes this 
hypothesis by means of electromyographic evaluation. Tinnitus sensation and other otologic symptoms, such as otalgia and hypoacusis, have been linked to the presence of $\mathrm{TMD}(\mathrm{s})$ in several studies, with four possible models that explain the etiology of otologic symptoms and signs in TMD(s): Embryological, muscular, bone communication and neural network. ${ }^{22}$

In the present study, subjects with articular symptoms associated or not with muscular complaints had higher incidence of otalgia and hypoacusis, although hearing loss had been declined by audiological testing. These findings agree with Ciacanglini et al, ${ }^{3}$ who also found significant association between the severity of arthropathy and the perception of audiological symptoms. Such complaints may be justified by the close relationship between TMJ, tympanic cavity and the Eustachian tube, ${ }^{2}$ in which the influence of changes in the contraction of the stapedius and cheekbone muscles on the ossicular chain of the middle ear and tympanic membrane, caused by the traction of the articular disc, could impact hearing perception, with otalgia related to central exciting effects and neuromuscular mechanisms involved in the TMD. ${ }^{22}$

The present study identified no changes in audiological tests, corroborating the literature. ${ }^{8,20}$ In addition it also found proper tubal function (type A curve) for all subjects, also discovered in other studies. ${ }^{8,20}$ However, it disagrees with a similar study ${ }^{25}$ that found lower pure tone air-conduction thresholds in $6000 \mathrm{~Hz}$ and $8000 \mathrm{~Hz}$ frequencies in TMD patients.

It is worth considering the limitations of this study: the heterogeneity of dentofacial deformities present in each studied group as well as the lack of control group with dentofacial balance. Further studies shall be conducted in this direction, attempting to better understand the relationships between malocclusion, temporomandibular dysfunction and audiological/vestibular signs and symptoms.

\section{CONCLUSION}

This study found that audiological symptoms are present in subjects with temporomandibular disorders and dentofacial deformities, regardless of TMD classification (articular, muscular or mixed). Subjects with mixed TMD may have higher incidence of complaints of hypoacusis than subjects with muscular TMD, however, with neither hearing loss, diagnosed by audiological testing, nor tympanometric alterations being observed in the research population.

Since this study is preliminary, we highlight the importance of carrying out further studies, with bigger casuistry, in order to investigate the possible relationship between audiological symptomatology and TMD(s) classification. 


\section{REFERENCES}

1. Bianchini EMG. Articulação temporomandibular e fonoaudiologia. In: Ferreira LP, Befi-Lopes DM, Limongi SCO, organizadores. Tratado de fonoaudiologia. São Paulo: Roca; 2009. cap. 57, p. 532-44.

2. Bubon MS. Documented instance of restored conductive hearing loss Funct Orthod. 1995:12(1):26-9.

3. Ciacanglini R, Loreti P, Radaelli G. Ear, nose, and throat symptoms in patients with TMD: the association of symptoms according to severity of arthropathy. J Orofacial Pain. 1994:8(3):293-7.

4. Conti PC, Ferreira PM, Pegoraro LF, Conti JV, Salvador MC. A crosssectional study of prevalence and etiology of signs and symptoms of temporomandibular disorders in high school and university students J Orofac Pain. 1996:10(3):254-62

5. Conti A, Freitas M, Conti P, Henriques J, Janson G. Relationship between signs and symptoms of temporomandibular disorders and orthodontic treatment: a cross-sectional study. Angle Orthod. 2003;73(4):411-7

6. Costen JB. Syndrome of ear and sinus simptons dependent upon disturbed functions of the temporomandibular joint. Ann Otol Rhinol Laryngol. 1934:43:1-15

7. Dworking SF, LeResche L, editors. Research diagnostic criteria for temporomandibular disorders: review, criteria, examinations and specifications, critique. J Craniofamandib Disord. 1992:6:301-55.

8. Felício CM, Oliveira JAA, Nunes LJ, Jeronymo LFG, Jeronymo RRF. Alterações auditivas relacionadas ao zumbido nos distúrbios otológicos e da articulação têmporo-mandibular. Rev Bras Otorrinolaringol. 1999:65(2):141-6

9. Felício CM, Faria TG, Silva MAMR, Aquino AMCM, Junqueira CA Temporomandibular disorder: relationship between otologic and orofacial symptoms. Rev Bras Otorrinolaringol. 2004;70(6):786-93.

10. Helkimo M. Studies on function and dysfunction of the masticatory system. II. Index for anamnestic and clinical dysfunction and occlusal state. Svensk Tandläk T. 1974;67(2):101-21.

11. Keersmaekers K, De Boever JA, Van den Bergue L. Otalgia in patients with temporomandibular joint disorders. J Prosthet Dent. 1996;75(1):72-6.

12. Kogawa EM. Avaliação da discriminação interoclusal para microespessuras e da força máxima de mordida em pacientes portadores de disfunções temporomandibulares [dissertação]. Bauru (SP): Universidade de São Paulo; 2005

13. Koh H, Robinson PG. Occlusal adjustment for treating and preventing temporomandibular joint disorders. J Oral Rehabil. 2004;31(4):287-92.

14. Kuttila S, Kuttila M, Le Bell Y, Alanen P, Jouko S. Aural symptoms and signs of temporomandibular disorder in association with treatment need and visits to a physician. Laryngoscope. 1999:109(10):1669-73.

15. McNamara JA, Seligman DA, Okeson JP. Occlusion, Orthodontic treatment, and temporomandibular disorders: a review. J Orofacial Pain. 1995:9(1):73-90.
16. Mohlin B, Axelsson S, Paulin G, Pietilä T, Brattström V, Hansen K, et al. TMD in relation to malocclusion and orthodontic treatment. Angle Orthod. 2007:77(3):542-8

17. Myrhaug $\mathrm{H}$. The incidence of ear symptoms in cases of malocclusion and temporomandibular joint disturbances. Br J Oral Surg. 1964; 2(1):28-32.

18. Okeson JP. Dor orofacial: guia de avaliação, diagnóstico e tratamento. The American Academy of Orofacial Pain. Chicago: Quintessence; 1998.

19. Parker WS, Chole RA. Tinnitus, vertigo and temporomandibular disorders Am J Orthod Dentofac Orthop. 1995 fev;107(2):153-158.

20. Penkner K, Köle W, Kainz J, Schied G, Lorenzoni M. The function of tensor veli palatine muscles in patients with aural symptoms and temporomandibular disorder. An EMG study. J Oral Rehabilitation. 2000:27(4):344-8

21. Pereira KNF, Andrade LLS, Costa MLG, Portal TF. Sinais e sintomas de pacientes com disfunção temporomandibular. Rev CEFAC 2005; 7(2):221-8

22. Ramirez LM, Ballesteros LE, Sandoval GP. Topical review: temporomandibular disorders in an integral otic symptom model. Int J Audiology. 2008;47(4):215-27.

23. Redondo MC, Lopes Filho O. Testes básicos de avaliação auditiva. In Lopes Filho O, et al. Tratado de Fonoaudiologia. 2. ed. Ribeirão Preto: Tecmedd, 2005. p. 89-110

24. Reis AC, Hotta TH, Ferreira-Jerônymo RR, Felício CM, Ribeiro RF. Ear symptomatology and occlusal factors: a clinical report. J Prosthet Dent 2000:83(1):21-4

25. Rodrigues ACY, Berretin-Felix G, Jorge JC, Genaro KF. Caracterização das alterações miofuncionais orais e auditivas em individuos com disfunção temporomandibular. Pró-Fono. 1998;10(1):51-5.

26. Silveira AM, Feltrin PP, Zanetti RV, Mautoni MC. Prevalência de portadores de DTM em pacientes avaliados no setor de otorrinolaringologia. Rev Bras Otorrinolaringol. 2007;73(4):528-32

27. Thilander B, Rubio G, Pena L, de Mayorga C. Prevalence of temporomandibular dysfunction and its association with malocclusion in children and adolescents: An epidemiologic study related to specified stages of dental development. Angle Orthod. 2002;72(2):146-54

28. Tuz HH, Onder EM, Kisnisci RS. Prevalence of otologic complaints in patients with temporomandibular disorder. Am J Orthod Dentofacial Orthop. 2003:123(6):620-23

29. Williamson $\mathrm{EH}$. The inter-relationship of internal derangements of the temporomandibular joint, headache e vertigo and tinnitus: a survey of 25 patients. J Craniomand Pract. 1990;8(4):301-6

30. Zeigelboim BS, Jurkiewicz AL, Martins-Basseto J, Klagenberg KF Avaliação vestibular em mulheres com disfunção temporomandibular Rev CEFAC. 2007:9(2):255-62 